\title{
The impact of Kaizen: Assessing the intensive Kaizen training of auto-parts suppliers in South Africa
}

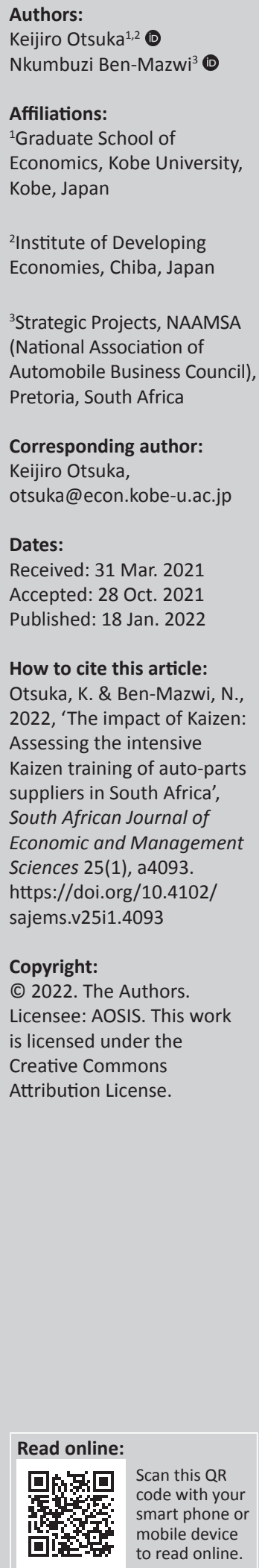

Background: There has been a growing recognition that the most critical missing factor impeding the growth and productivity of manufacturing enterprises in developing countries is entrepreneurs with strong managerial abilities. As Kaizen requires strong communication and cooperation between managers and shop-floor workers, social cohesion between them seems to be a prerequisite for its successful implementation.

Aim: The question arises whether Kaizen can improve efficiency in management in a place like South Africa, a country marked by serious ethnic divisions. Therefore, the aim in this study is to assess the impact of an intensive Kaizen training programme in South Africa.

Setting: So an intensive Kaizen training programme was implemented at eight randomly selected automotive parts-suppliers in the three key automotive regions in South Africa from 2016 to 2019.

Method: A combination of a standard survey questionnaire and informal interviews was used to collect the production and management data. Given our relatively small sample size, the analysis is descriptive in nature.

Results: Evidence shows that Kaizen, a Japanese management system, is indeed effective in improving the performance of enterprises in developing countries.

Conclusion: The Kaizen method proves to be so successful in improving efficiency in South Africa that it justifies scaling up such a training programme in the future.

Keywords: Kaizen; managerial ability; management training; enterprise performance; automotive industry; auto-parts industry; social cohesion; South Africa.

\section{Introduction}

Innovations in industrial clusters are well known to be key to the successful deployment of manufacturing industries in developing countries. Stagnant industrial clusters without innovation and dynamic clusters with active innovation have both already been described in case studies in developing countries in Asia and Africa (Sonobe \& Otsuka 2006, 2011, 2014), as well as in a comparative study of development in industrial clusters in history and in the developing world (eds. Hashino \& Otsuka 2016). In this study, 'innovation' refers to any changes that improve productivity, rather than Schumpeterian breakthroughs. Within the South African context, the importance of innovation for success has been clearly recognised historically. Madi (2000) credits Shaka's success in uniting many tribes in the Zulu Kingdom to his invention of the iklwa, a short spear that could be used in place of the traditional throwing spear.

Literature clearly established that a major constraint on growth in manufacturing firms in developing countries is the lack of human capital, in general, and managerial human capital, in particular (e.g. Bertrand \& Schoar 2003; Bloom \& Van Reenen 2010; Bloom et al. 2020; Bruhn, Karlan \& Schoar et al. 2010, 2018). In these studies it is found that management practices and enterprise performance are strongly correlated. A historical study by Giorcelli (2019) reveals that Italian entrepreneurs who were invited to the U.S. for management training later improved and expanded their businesses significantly. It thus appears likely that managerial human capital is vitally important for innovation or improvements in production efficiency in firms.

Particularly noteworthy is the critical role of Kaizen, a Japanese management system, in stimulating innovation in manufacturing enterprises primarily through cost reductions (Harada 2015; Imai 1997; Kaplinsky 1994; eds. Otsuka, Jin \& Sonobe 2018; Sonobe \& Otsuka 2014). Randomised controlled trials (RCTs) have been conducted to assess the effects of Kaizen training 
in small enterprises, employing 5 to 25 workers in industrial clusters in three countries: one in a metal works cluster in Ghana (Mano et al. 2012); another in garment and steel bar clusters in Vietnam (Higuchi, Nam \& Sonobe 2015); and a third in a garment cluster in Tanzania (Higuchi, Mhede \& Sonobe 2019). The training programmes commonly employ not only standard business training (in fields such as entrepreneurship, marketing, and accounting), but also a Japanese-style management called Kaizen (or the continuous improvement in production management and quality control). Kaizen seeks to save costs and adopt a commonsense approach, focused on reducing waste through the elimination of inventories, equalising the work burdens on all workers in a production line, quality management, routinised machine maintenance, and the maintenance of clean and uncluttered work-spaces. Since Kaizen has proven to be highly effective, it may be no exaggeration to argue that it has been widely adopted by almost all the successful manufacturing enterprises in developed countries in Asia (Jin 2018; Kaplinsky 1994).

The automotive clusters in South Africa are stagnant, largely as a consequence of a failure in auto-parts production sectors to grow. In response, the Automotive Industry Development Centre (AIDC) collaborated with the Japan International Cooperation Agency (JICA) to offer an intensive Kaizen training programme to selected first-tier auto-parts suppliers from 2016 to 2019. In this study, we focus on eight companies trained in Kaizen. Because of trials and errors in the process and occasional changes in these companies, training was done in seven companies for a few years and in one company for less than a year. As the implementation of Kaizen requires active communication and cooperation between managing directors (MDs), managers, and shop-floor workers, the social cohesion among them is considered to be critically important. Yet social cohesion can be a serious challenge in South Africa, a country ridden with ethnic divisions, particularly between the African, Coloured, Indian, and the white populations. Thus, whether Kaizen could be effective in this country is an important empirical question. Another related issue is the extent to which the adoption of Kaizen promotes social cohesion, given that this becomes particularly valuable when Kaizen is implemented. Shimada and Sonobe (2021) found that the introduction of Kaizen strengthened social capital in Central America and in the Caribbean region. Kaizen has also been used in the Philippines to promote social cohesion among the indigenous people (Abadiano 2020).

In this study it is attempted to assess the impact of an intensive Kaizen training programme, offered by the AIDC, on the efficiency of enterprise management. As our sample included only eight companies, we have no way to draw definitive conclusions. Our aim in this study is to identify evidence that the adoption of Kaizen has brought about significant improvements in the efficiency of management that may be reflected in improvements in performance indicators, such as increased labour productivity and decreased lead time. We presume that findings of significant improvement in management indicators will justify scaling up Kaizen training programmes in the future.

This paper is organised as follows. In the section 'Kaizen principles and expected changes' the principles of Kaizen and expected changes in production activities are briefly explained, while in 'Kaizen tools' the major Kaizen tools are discussed. This is followed by an explanation of the major characteristics of the selected companies in 'Major characteristics of the selected companies'; a description of the composition of a Kaizen team in 'Kaizen team and workers' attitude for change'; and an assessment of the impact Kaizen training has in the section 'An assessment of changes in management efficiency'. Finally in 'Concluding remarks' the major findings are summarised and the course of future studies on the auto-parts industries in South Africa proposed.

\section{Kaizen principles and expected changes}

Sonobe (2018:4) defines Kaizen as the management philosophy and know-how that brings about continuous, participatory, incremental, low-budget improvements in quality, productivity, cost, delivery, safety, morale, and environment'. Kaizen is human friendly and participatory, because it is designed to utilise a collection of ideas and insights that managers and workers create and refine through observations and experiments in cooperation. Kaizen improves productivity in an incremental, progressive, and step-by-step manner. Sugimoto (2018:71) argues that 'Kaizen can be defined as activities that fill the gap between the current state and the ideal state by solving problems or achieving tasks on an operational level'. Thus, to be successful, a company practising Kaizen must understand the current state, identify the ideal state, and possess the will to fill the gap between the two.

The gap between the current state and ideal state is typically revealed by wasteful or non-value-adding activities (muda). In order to increase profit, Kaizen emphasises cost reduction, particularly at its basic stage, through the elimination of any form of waste or muda, rather than directly pursuing the production of high-quality, high-priced products or increased sales volume. This is reasonable, as innovation in the process of cost reduction is more feasible than the innovation in creating new products for companies in developing countries. Note, however, that advanced Kaizen is designed to contribute to improvement in the quality of products, as well as the creation of incremental innovations. Consequently, we shall mainly examine changes in management indicators related to cost reduction in the section 'An assessment of changes in management efficiency'. Needless to say, cost reduction leads not only to higher labour productivity, but also to higher total factor productivity, which in turn leads to higher production volume in the longer run. The increase in total factor productivity may not be as great as the increase in labour productivity, to the extent that the implementation of Kaizen requires an increased number of labourers and new 
investment in equipment and machines. Large new investments, however, are seldom required for Kaizen. Thus, we shall compare labour productivity before and after the introduction of Kaizen in 'Concluding remarks'.

If Kaizen is implemented thoroughly, fewer workers will be needed, though labor productivity will rise accordingly. It is strongly recommended that the workers made redundant by the labour-saving improvement, should not be fired, as firing reduces the workers' incentives to adopt Kaizen. These 'redundant' workers should instead be shifted to other productive activities. According to Harada (2015), the most productive workers should be shifted to other challenging tasks. This approach forms a strong pool in middle management that drives the implementation of Kaizen. We shall examine whether the introduction of this method actually decreases the required manpower in the sampled companies. Note, also, that since Kaizen is expected to improve efficiency in production, it will increase the number of employees in the longer run. We shall therefore examine the changes in the number of employees over time.

As the production system must be reformed considerably in order to implement Kaizen, mutual understanding and cooperation among MDs, engineers, shop-floor managers, and shop-floor workers are indispensable. Kaizen experts therefore recommend that a Kaizen team be appointed, consisting of MDs, engineers, and shop-floor managers, among others, also that weekly meetings for this team be held. The commitment of the MD to the implementation of Kaizen is also strongly recommended, given that substantial changes in a production system can only be executed with the deep involvement and clear consent of the MD as the major decision-maker. Indeed, Bandiera et al. (2018) find that the working hours of chief executive officers are a critical determinant in the performance of the enterprise. Any negative attitude of workers towards the introduction of Kaizen is particularly problematic, as the workers do not immediately understand the impact it has. One of the roles of the MD is to convey the usefulness of Kaizen to the shopfloor workers. Thus, we examine the composition of the Kaizen team, the participation of MDs in Kaizen meetings as a proxy for their commitment, and the receptiveness of the shop-floor workers to changes in the production system associated with the introduction of Kaizen.

The question is how to eliminate muda (non-value-adding activities). Overproduction is considered to be the most serious muda, simply because an inventory of unsold products is of no value. Therefore, Kaizen recommends a production pull system whereby instructions are issued from the final process to the upstream processes to ensure that the required volume of products is produced in correspondence with the actual orders. Just-in-time is enforced to provide needed materials on time, and the process is tracked by signboards or kanban. This production system facilitates the on-time delivery of products without holding inventory. The extent to which on-time delivery becomes more common after Kaizen is introduced, will be probed. Because the Kaizen project was applied to a particular production line during training, it made no sense to examine changes in the inventory of final products in this study.

Harada (2015) argues that waiting time, inspection time, and transport time are all muda, while only processing time is valuable, because only processing adds value. He also argues that work in progress must be reduced as much as possible, that inspection time should be reduced by producing only acceptable products, and that the production line must be designed to minimise transportation time. Kaplinsky (1994) points out that work in progress is held back just in case something unexpected goes wrong. The existence of stock, however, absorbs shocks (e.g. machine breakdown), and hence conceals the sources of a problem. On the other hand, the elimination of stock exposes any problems on the production floor, because the solution can be quickly spotted when the production process is interrupted. Otherwise, the production process continues and defects accumulate. Thus, Kaizen recommends that the stock of unfinished goods be reduced to the lowest level possible. In consequence, the percentage of defects, or the rejection rate, is expected to be reduced. In quantitative analyses, the reduction in the number of work in progress and in the rejection rate after Kaizen is introduced, is looked into.

A reduction in the stock of incomplete products requires continuous one-piece flow processing, a method in which the workers in the same production lines must share an equal workload. Hence, when workers complete their tasks and hand over pieces of work in progress to the next process, the next set of workers must have just completed their tasks, and be ready to receive the new pieces. The equipment and machine locations, processing methods, and distribution of workloads must be carefully designed to achieve this flow. When a continuous production process with one-piece flow, rather than batch production, is achieved, the manufacturer will reduce the stock of work in progress, as well as the lead time; that is, the sum of the processing time and the waiting time during which the flow of material is stagnant. Work is thus completed faster, which increases labour productivity and the likelihood that errors are more immediately spotted. Overtime work is reduced as a result, and the working hours spent per day (or per shift) tend to be curtailed. Thus, we shall analyse the extent of the changes in lead time and overtime work.

\section{Kaizen tools}

Imai (1997), Sugimoto (2018), and others have offered detailed descriptions of the numerous Kaizen tools in use. Our discussion in this section will therefore be brief, drawing on AIDC (2019).

The most well-known and the most basic tool is the 5S methodology: (1) sort; (2) set in order; (3) shine; (4) standardise; and (5) sustain. 'Sorting' is the process of sorting all items, and removing the unnecessary ones, so as to reduce 
time lost looking for items and to increase available space. 'Setting in order' means putting necessary items in the best places to achieve a smooth and easy workflow. If these 2Ss are implemented, efficiency of work improves as tools and materials can be easily found when needed. When the shop floor is 'shined', or cleaned, the safety of the workplace improves, abnormalities can be quickly detected, and inefficiencies in the production system can be easily identified. 'Standardised' production processes are processes in which the first 3Ss are repeatedly or continuously applied. 'Sustained' processes are processes in which workers are selfdisciplined, or 'do without being told'. Once the 5S methodology is implemented, the work place becomes tidy, which makes it easier to notice problems or muda. The 5S methodology must therefore be implemented before applying the more advanced tools of Kaizen.

A material and information flow diagram (MIFD) is a powerful tool used to visualise the flow of material and information on the shop floor, evaluate the lead time, and identify the causes of work in progress accumulating. In other words, a MIFD identifies problematic areas that need improvement in order to reduce the amount of work in progress. A MIFD, which is similar to a lean tool called VSM (Value Stream Mapping), also provides a visual map of how various tasks are interrelated.

The establishment of standardised work is essential, as it seeks to create an efficient production sequence. In standardised work, tasks are combined to coordinate workers, machines, and materials in the most efficient manner so as to eliminate the 3Ms (muda, mura, and muri): (1) $M u d a$, or any waste in the production process; (2) Mura, or unequal workloads on people or machines; and (3) Muri, or unreasonable burdens on people or machines.

Ultimately, the crux of Kaizen is to continuously improve production systems by coordinating all members of a company, ranging from the MD to the managers, and further to all of the shop-floor workers. Crucially, the shop-floor workers must recognise the value of Kaizen and come up with new ideas, as they are the ones who apply new production systems and are optimally positioned to identify the problems to be solved.

Our main hypothesis is that Kaizen demands significant efficiency in management which increases productivity in labour and delivery on time, reducing incomplete work, rejection rates, overtime work, and lead time. While the required labour for completing given tasks may decline, we expect the number of employees of the enterprises to increase, as the increased efficiency in management will result in expansion of the businesses overall.

\section{Major characteristics of the selected companies}

A mixed research method that uses both the quantitative and qualitative approach in addressing the research problem was employed, while the analysis is descriptive in nature. A combination of a standard survey questionnaire and informal interviews was used to collect the production and management data. A simple random sample of eight automotive auto-parts suppliers were selected from each of the three key automotive regions in South Africa, which are Gauteng Province (including Johannesburg and Pretoria), KwaZulu Natal (including Durban), and the Eastern Cape (including Port Elizabeth and East London). Four of the eight companies are located in Gauteng, two are located in the Eastern Cape, and two in KwaZulu Natal (see Table 1). All of them are first-tier auto-parts suppliers that directly deliver their products to automotive assemblers. Their customers, the automotive assemblers, represent almost all of the major global automotive companies in the world. Two of the auto-parts manufacturers were established as early as in the 1960s, and two were established as recently as the 2010s. The average year of establishment of the eight companies is 1992. Two of the companies are joint ventures (JVs) with enterprises in Europe or Japan. Although we can hardly claim that these eight companies are representative, our intention was to choose 'typical' auto-parts suppliers.

Judging from the number of workers shown in Table 2, three to four of the selected companies are small-sized, employing 10 to 100 persons; two are medium-sized, employing 100 to 250 workers; and the rest are large companies, employing more than 250 workers. The years in operation correlate positively with the sizes of these companies, which probably reflects differences in the accumulation of skills and know-how. Most notably, the number of employees in the sixth company, which is the newest, increased five-fold in three years. The number of employees of one JV (No. 4) is relatively large, while that of the other JV (No. 5) is small, with new employees. We were interested to observe that the average number of workers increased from 135 in 2015, just before the Kaizen training programme began, to 193 in 2018, after the training had been offered for a couple of years. This increase in the number of workers may suggest that the Kaizen training had a positive impact on these companies through cost reduction. Table 2 also shows the proportion of direct workers (or shop-floor workers). While this proportion varies from company to company, about three-quarters of the workers on average were

TABLE 1: Year of establishment, foreign affiliation, location, and major products.

\begin{tabular}{llll}
\hline Company code & Year of establishment & $\begin{array}{l}\text { Joint venture (JV) } \\
\text { or Local (L) }\end{array}$ & Location \\
\hline 1 & 2005 & L & Eastern Cape \\
2 & 1970 & L & Gauteng \\
3 & 2002 & L & Gauteng \\
4 & 1960 & JV & Kwazulu Natal \\
5 & 2013 & JV & Kwazulu Natal \\
6 & 2014 & L & Eastern Cape \\
7 & 1963 & L & Gauteng \\
8 & 2008 & L & Gauteng \\
Average & 1992 & $-\dagger$ & $-\dagger$ \\
\hline
\end{tabular}

$\dagger$, Not relevant. 
engaged directly in production activities in both 2015 and 2018. Most of these workers are African and Coloured people.

As may be expected, white people accounted for the largest share of managers in all but a few of the companies. Yet, their average share declined from 58\% in 2015 to 51\% in 2018, while the share of African managers increased from $20 \%$ to $27 \%$ over the same period. While it remains unclear whether or not these changes are significant, the introduction of Kaizen may have increased management roles for the African employees. If Kaizen did have such an effect, it might indicate that social cohesion improved to some extent. The share of Indian workers is large, mainly in the two companies located in KwaZulu Natal (30\% to $50 \%$ ), where the population of Indian descent is relatively large.

These companies generally used to apply a top-down management system, as McKee (1999) explains. This hierarchical and control-oriented system is unsuited to today's rapidly changing organisational structure in the African culture. The management style is also inconducive to efficient corporate management. This is a characteristic of the selected companies in which the Kaizen principles were applied.

TABLE 2: Number of workers and proportion of direct workers before (2015) and after (2018) Kaizen training.

\begin{tabular}{lcccccc}
\hline Company code & \multicolumn{2}{c}{ Number of workers } & & \multicolumn{2}{c}{ Proportion of direct workers (\%) } \\
\cline { 2 - 3 } \cline { 6 - 6 } & $\mathbf{2 0 1 5}$ & $\mathbf{2 0 1 8}$ & & $\mathbf{2 0 1 5}$ & $\mathbf{2 0 1 8}$ \\
\hline 1 & 66 & 61 & & 65 & 51 \\
2 & 261 & 260 & & 88 & 94 \\
3 & 100 & 111 & & 95 & 91 \\
4 & 269 & 415 & & 79 & 83 \\
5 & 56 & 80 & & 38 & 55 \\
6 & 59 & 322 & & 85 & 73 \\
7 & 238 & 0 & & 62 & 47 \\
8 & 34 & 32 & & $-\dagger$ & 86 \\
Average & 135 & 193 & & 73 & 73 \\
& $(150) \ddagger$ & $(217) \ddagger$ & & - & $(71) \ddagger$ \\
\hline
\end{tabular}

$\dagger$, Not relevant.

$\$$, Average, excluding company 8 .

\section{Kaizen team and workers' attitude towards change}

As mentioned earlier, Kaizen experts recommended that the relevant companies form cross-functional Kaizen teams. Top managers are team members in general, while engineers and shop-floor managers are team members without exception. The inclusion of engineers, particularly industrial engineers, is important, as they are adept at the mechanical aspects of production management. Although not shown in the table, four companies increased the number of industrial engineers employed from 2015 to 2018.

The shop-floor managers are also essential team members, as they can effectively facilitate communication between the top managers and shop-floor workers, thus fulfilling an indispensable function for the successful implementation of Kaizen. Many of the engineers and shop-floor managers are non-white people, accounting for about $70 \%$ of the Kaizen team members on average. Note, however, that many of them were junior engineers who were introduced to the companies by AIDC. They appear to be actively involved in newly introduced Kaizen methods, which may reflect the improved social cohesion between the different ethnic groups.

The Kaizen meeting is held once a week for at least $1 \mathrm{~h}$ in most cases, as recommended (Table 3). According to the Japanese Kaizen experts, the commitment of the MDs to its implementation, is key to the successful introduction of Kaizen. Pretorius (2013) points out that the core tasks of leadership are to direct, inspire, enable, focus, and change the behavior of employees, through commitment. The other important aspect, according to Harada (2015), is that the foreman or leader on the shop-floor is the person who actually breaks the standard. This is understandable, insofar as the MD is a major decision-maker in the company. Some MDs, however, fail to recognise the importance of Kaizen and consequently withhold their active support of its implementation. Although it is hard to assess accurately the

TABLE 3: Kaizen meeting and change in the workers' attitude between before (2015) and after (2018) Kaizen training.

\begin{tabular}{|c|c|c|c|c|c|c|}
\hline \multirow[t]{2}{*}{ Company code } & \multirow[t]{2}{*}{ Training period $\dagger$} & \multicolumn{2}{|c|}{ Kaizen meeting } & \multicolumn{3}{|c|}{ Workers' attitude $\llbracket$} \\
\hline & & $\begin{array}{l}\text { How often } \\
\text { (hours) }\end{array}$ & $\begin{array}{c}\begin{array}{c}\text { How long per meeting } \\
\text { (hours) }\end{array} \\
\end{array}$ & $\begin{array}{l}\text { Participation of MD } \\
\text { (hours) }\end{array}$ & 2015 & 2018 \\
\hline 1 & $10 / 2016-06 / 2019$ & 1/week & $1 \sim 2$ & $1 /$ month & 4 & 4 \\
\hline 2 & $10 / 2017-03 / 2019$ & 1/week & 2 & $1.5 /$ month & 3 & 3 \\
\hline 3 & $11 / 2016-07 / 2019$ & 1/week & $6 \$$ & 1/week & 1 & 4 \\
\hline 4 & $11 / 2015-07 / 2019$ & 1/week & 1 & $0.5 /$ week & 2 & 4 \\
\hline 5 & $11 / 2017-05 / 2019$ & 1/week & 2.5 & 1/week & 2 & 4 \\
\hline 6 & 07/2017-06/2019 & 1/week & 1 & 0 & 4 & 5 \\
\hline 7 & 09/2016-07/2019 & 0 & 2 & $1.5 /$ month & 3 & 5 \\
\hline 8 & 09/2018-07/2019 & 1/week & $0.25 \sim 0.5$ & $2 /$ month & 2 & 4 \\
\hline Average & $-\S$ & 1/week & $-\S$ & $-\S$ & 2.6 & 4.1 \\
\hline
\end{tabular}

$\dagger$, Months are expressed from 1 (January) to 12 (December). Two companies did not specify the month.

$\$$, Not all stakeholders meet together.

$\S$, Not relevant.

I, Numbers correspond to the following five categories: 1 , Very resistant to change; 2 , Resistant to change; 3 , Not resistant, not receptive; 4 , Receptive to change; 5 , Very receptive to change. 
commitment of MDs, Table 3 shows the level of MD participation in the weekly Kaizen meeting as an indicator of the MDs' commitment. According to this indicator, the MDs of the third and fifth companies are the most active in the implementation of Kaizen, while the MD of the sixth company is inactive, delegating the overall responsibility for implementation to a junior engineer. It thus becomes worthwhile to examine whether the management performance improved more significantly in the third and fifth companies than in the others, particularly in the sixth company. We must note, however, that if the MDs in those two companies are more competent than those in the others, in general, then the improvement in efficiency in management of those companies cannot be wholly attributed to the commitment of their MDs to Kaizen. We may also note that the sixth company is new and started the business from a zero base.

We repeatedly heard during the informal interviews that the shop-floor workers were highly resistant to changes associated with the introduction of Kaizen, believing that their methods were already efficient enough. The same tendency was observed in Central America and the Caribbean by Shimada and Sonobe (2021), where employees were initially skeptical about the usefulness of Kaizen. To convince the shop-floor workers that new methods are superior, trainers had to demonstrate their superiority by showing actual improvements. We were told that once the superiority of Kaizen was successfully demonstrated, the workers' attitudes changed markedly. Thus, we asked the workers about their attitudes towards the changes before and after the Kaizen training in our questionnaire survey.

As is demonstrated in the last two columns of Table 3, their attitudes changed from between 2 ('resistant to change') and 3 ('not resistant, not receptive') to 4 ('receptive'). Another interesting point to confirm was the remarkable change in the workers' attitudes in the third and fifth companies, where the MDs always participated in the weekly Kaizen meetings. This finding is consistent with Bandiera et al. (2018), who find that the working hours of MDs are a critical determinant in the performance of enterprises. A substantial change was also seen in the workers' attitude in the eighth company, where the MD often participated in the Kaizen team meetings (see Table 3). It would probably be fair to conjecture that there were clear changes in workers' attitudes towards accepting the new production systems introduced by Kaizen in most of the sampled auto-parts manufacturers.

\section{An assessment of changes in management efficiency}

There is significant evidence, based on the RCT in the literature, that management training improves not only the management practices (e.g. quality control, inventory management, sales, return on assets, and profit), but also the performance of small to medium enterprises in cotton weaving plants in India (Bloom et al. 2013) and manufacturing, commerce, and service enterprises in Mexico (Bruhn et al. 2018). According to a resurvey at the same plants by Bloom et al. (2020), moreover, the intervention generated a persistent or long-term impact on plants in India. Bruhn et al. (2018) find similarly the long-term impact of management training on employment generation.

The results of management training for microenterprises with few or no paid employees are puzzling. According to a survey of 13 RCT-based studies by McKenzie and Woodruff (2014), most studies find the significant impact management training has on the adoption of improved management practices, without finding a statistically significant impact on the firm's profitability. Another survey by McKenzie and Woodruff (2017) basically supports their earlier data. They identify the following as possible causes for their results: (1) small sample size, (2) assessment of very short-run impacts, (3) large heterogeneity of sample enterprises, (4) short training courses, and (5) focus on microenterprises. While the sample size is very small in our study, the changes were being assessed over a three-year period between 2016 and 2019, the sample enterprises were all engaged in the production of automotive parts (heterogeneity is not a serious constraint), the training course was extended rather than brief, and the enterprises were small to medium. We presume that improved management is more important in small to medium enterprises than in microenterprises, as the monitoring and coordination are more costly in the former than the latter. Therefore, we expect to observe the large and economically meaningful effects of management training going forward in this study. McKenzie (2020) attributes the lack of significant management training effects on the performance of enterprises to low powers of statistical analyses. In fact, his meta-analysis demonstrates small but significant effects of management training on the performance of microenterprises.

While the best indicator of improvement in productivity is the change in the total factor productivity, difficulties in assessing the value of capital makes it practically difficult to compute this change. Since Kaizen is designed to achieve low-cost improvement in productivity without much extra investment in equipment, changes in labour productivity can be a reasonable proxy for improvement in the total factor productivity. In order to improve efficiency in management, however, some investments in new equipment may be necessary. Increased labour productivity is also consistent with a company's current policies as it searches for new ways to achieve higher-quality communication, greater speed in making decisions, increased creativity and problem solving, and improved customer services (McKee 1999).

As shown in Table 4, labour productivity, measured by the number of products divided by the number of workers in the targeted production line in Kaizen training, on average more than doubled within three years. Note that Kaizen is not applied to the entire production system, but to selected production lines. Moreover, the third company increased its labour productivity by as much as four times. The MD of the 
TABLE 4: Change in labor productivity within regular working hours in the targeted production line between before (2015) and after (2018) Kaizan training.

\begin{tabular}{|c|c|c|c|}
\hline \multirow[t]{3}{*}{ Company code } & \multicolumn{3}{|c|}{ Production per worker within regular working hours } \\
\hline & 2015 & 2018 & Ratio \\
\hline & $(1)$ & $(2)$ & $(2) /(1)$ \\
\hline 1 & $-\dagger$ & $-\dagger$ & $-\dagger$ \\
\hline 2 & 94.5 & 143.3 & 1.52 \\
\hline 3 & 4.6 & 18.8 & 4.09 \\
\hline 4 & 30 & 105 & 3.5 \\
\hline 5 & 600 & 850 & 1.42 \\
\hline 6 & 60 & 74 & 1.23 \\
\hline 7 & 82.5 & 120 & 1.45 \\
\hline 8 & 0.011 & 0.025 & 2.27 \\
\hline Average & $-\hbar$ & $-t$ & 2.21 \\
\hline
\end{tabular}

$\dagger$, Not available.

$\$$, Not relevant, because the measurement units differ.

TABLE 5: Change in the proportion of on-time delivery (\%) and work-in-progress between before (2015) and after (2018) Kaizen training.

\begin{tabular}{|c|c|c|c|c|c|c|}
\hline \multirow{3}{*}{$\begin{array}{l}\text { Company } \\
\text { code }\end{array}$} & \multicolumn{3}{|c|}{ On-time delivery (\%) } & \multicolumn{3}{|c|}{ Work-in-progress } \\
\hline & 2015 & 2018 & Difference & 2015 & 2018 & Ratio \\
\hline & (1) & (2) & $(2)-(1)$ & (3) & (4) & $(4) /(3)$ \\
\hline 1 & 100 & 100 & 0 & 7.016 & 0 & 0 \\
\hline 2 & 73 & 94 & 21 & $-\dagger$ & $-\dagger$ & $-\dagger$ \\
\hline 3 & 95 & 98 & 3 & 3,600 & 13 & 0.004 \\
\hline 4 & 30 & 90 & 60 & 4,563 & 1,354 & 0.297 \\
\hline 5 & 80 & 98 & 18 & 650 & 13 & 0.02 \\
\hline 6 & 70 & 85 & 15 & $-\dagger$ & $-\dagger$ & $-\dagger$ \\
\hline 7 & 100 & 100 & 0 & $-\dagger$ & $-\dagger$ & $-\dagger$ \\
\hline 8 & $-\dagger$ & $-\dagger$ & $-\dagger$ & $-\dagger$ & $-\dagger$ & $-\dagger$ \\
\hline Average & $78.3 \%$ & $95.0 \dagger$ & $16.7 \ddagger$ & $-t$ & $-\dagger$ & $-\dagger$ \\
\hline
\end{tabular}

$\dagger$, Not available.

$\$$ Average of seven companies (company 8 excluded).

third company may have been strongly attracted to Kaizen, because of the low productivity before, which created ample room for improvement in productivity. The eighth company also more than doubled its labour productivity, and within a much shorter training period. In contrast, the sixth company recorded an improvement of only 23\%, far less than the average. Note that the MD of the sixth company did not participate in the weekly Kaizen meeting (see Table 3), which may suggest that a lack of strong commitment could have been a constraint on the effective implementation of Kaizen. Judging from the generally large increase in labour productivity, the impact of Kaizen on efficiency in production seemed enormous. We find little reason to doubt that the introduction of this method significantly improved productivity in the sample companies. Somewhat similar to our study, Iacovone, Maloney and McKenzie (2019) applied the RCT to management training in small to medium-sized automobile part-suppliers in Columbia, and they did not find any significant effect on performance. However, their training used standard business training programmes, and not Kaizen.

Several indicators support the hypothesis that the introduction of Kaizen increases efficiency in management or reduces costs. First, Table 5 shows the change in the proportion of products delivered on time from the targeted production lines before and after Kaizen training. As would be expected, the proportion of on-time delivery increased in
TABLE 6: Change in the average over-time working hours per week between before (2015) and after (2018) Kaizen training. $\dagger$

\begin{tabular}{|c|c|c|c|}
\hline \multirow[t]{2}{*}{ Company code } & 2015 & 2018 & Difference \\
\hline & $(1)$ & (2) & $(1)-(2)$ \\
\hline 1 & 6 & 13 & -7 \\
\hline 2 & 10.7 & 2.5 & 8.2 \\
\hline 3 & 48 & 8 & 40 \\
\hline 4 & 8 & 0 & 8 \\
\hline 5 & 10 & 0 & 10 \\
\hline 6 & 20 & 5 & 15 \\
\hline 7 & 8 & 8 & 0 \\
\hline 8 & 0 & 0 & 0 \\
\hline Average & 13.8 & 4.6 & 9.3 \\
\hline
\end{tabular}

$\dagger$, Regular working hours are assumed to be 40 hours per week.

most companies, albeit to a relatively modest degree, over the two years.

Secondly, although comparable data are only available from four companies, case study reports, submitted by the companies where training was done, to the AIDC provide additional valuable information on work in progress (Table 5). The volume of unfinished goods declined precipitously and almost disappeared at the first, third, and fifth companies. Furthermore, the required manpower declined by $26 \%$ on average. While there may have been selection biases to the extent of the reduction in work in progress and required manpower, the evidence provides added support for the significant impact of Kaizen on efficiency in management.

Thirdly, Table 6 shows the change in overtime working hours per week before and after Kaizen training. These data are important, given that overtime work was commonly performed to complete the required tasks before Kaizen was introduced. The overtime work, which the companies were forced to perform to compensate for low efficiency in production, involved costly extra payments. After the introduction of Kaizen, the working hours per week declined substantially in all companies but the first, seventh, and eighth. The first company reported that the working hours increased due to the increased volume in production, which could be a sign of successful management production, rather than persistently inefficient management, judging from the substantial reduction in work in progress shown in Table 5. Thus, we can generally conclude that improved efficiency in production brought about by the adoption of Kaizen led to significant declines in the work hours per week. Correspondingly, on average, the rejection rate declined from $3.3 \%$ in 2015 to $2.2 \%$ in 2018 . Note that the rejection rate is related to both the product quality and production cost.

Finally, Table 7 provides strong evidence that the lead time declined tremendously after Kaizen was introduced, which led to improved delivery on time to customers. On average, the lead time in 2018 declined to only 38\% of the 2015 level. This is highly consistent with labour productivity more than doubling as shown in Table 4. Particularly noteworthy is the decline in lead time to almost zero in the second, third, and fifth companies, versus the small decline in the seventh company. These findings support our hypothesis that the 
TABLE 7: Change in lead time in the targeted production line before (2015) and after (2018) Kaizen training (hours)

\begin{tabular}{lccccc}
\hline Company code & $\mathbf{2 0 1 5}$ & & $\mathbf{2 0 1 8}$ & & Ratio \\
\cline { 2 - 3 } \cline { 5 - 5 } \cline { 5 - 5 } & $\mathbf{( 1 )}$ & $\mathbf{( 2 )}$ & & $\mathbf{( 2 ) / ( 1 )}$ \\
\hline 1 & 14.1 & & 9.8 & \\
2 & 12.8 & & 1.2 & 0.69 \\
3 & 129 & & 0.3 & 0.09 \\
4 & 29.8 & & 8.8 & 0 \\
5 & 136.8 & & 0.58 & 0.3 \\
6 & 73 & & 42 & 0 \\
7 & 70 & & 51 & 0.57 \\
8 & 120 & & 75 & 0.73 \\
Average & $-\dagger$ & $-\dagger$ & 0.63 \\
\hline
\end{tabular}

$\dagger$, Irrelevant, because the activities differ.

introduction of Kaizen had a significant impact on efficiency in management. This effect is exceedingly important regarding the satisfaction of customers, that is, OEMs (Original Equipment Manufacturers), because shortened lead time assures on-time delivery.

To sum up, the collected data support the hypothesis that Kaizen has a significant impact on efficiency in management in the auto-parts industry in South Africa. While the impact of Kaizen on social cohesion is not known, we cannot imagine that Kaizen could improve efficiency in management in the sheer absence of improved social cohesion.

\section{Concluding remarks}

During the transition of the South African political landscape to a democratic state in 1994, most automotive OEMs in the country gained access to the global market. This brought increased international competition and a need for both improved quality and reduced cost in production. Many of the OEMs thus adopted Kaizen principles, which has since led to the sustainable success of the automotive industry in South Africa. The challenge now remains primarily to the supplier base, which is still inefficient and uncompetitive compared to global counterparts. There seems to be a clear need for Kaizen training in all the tiers of component suppliers in future.

Given our small sample size, it would be difficult to draw any clear-cut conclusions from the descriptive analyses in this study. We also face the constraint of missing data. Nonetheless, many of our findings suggest that the introduction of Kaizen significantly contributed to improvements in the efficiency in management in the autoparts companies where training was done. On this basis, we believe that further efforts to disseminate Kaizen to a large number of parts-producing companies in South Africa would be justified.

According to the Japanese experts, a major constraint on the wider dissemination of Kaizen in this country is the weak commitment of MDs. While there may be many reasons for this constraint, a lack of conclusive evidence of the significant impact of the Kaizen method may be core among them. Thus, we propose to implement Kaizen training in a much larger number of parts-suppliers in South Africa, in order to collect convincing statistical evidence to support the significant impact of Kaizen training. Particularly important is the development of second- and third-tier auto-parts sectors, the Achilles heel of the automotive industry in this country. Indeed, many parts potentially produced by second- and third-tier domestic suppliers are imported from Thailand.

The massive and increasing importation of components works against the SAAM (South African Automotive Masterplan) vision and policy for 2035. The projected drive for localisation and growth in the South African automotive industry, as per SAAM 2035, will not be realised without comprehensive Kaizen training and implementation, especially in the component manufacturers. Opportunities for developing such sectors in South Africa are becoming ripe, as rising labour costs may be eroding Thailand's comparative advantage in producing exported parts currently.

A larger sample size would not be enough to prove the significance of Kaizen. To more rigorously assess the 'pure' impact of Kaizen training, it will be appropriate to apply RCTs; that is, trials in which the training is offered only to randomly selected companies, in order to compare their performance with that of a randomly selected control group after training. Any differences in the efficiency of management identified in such trials could be attributed to the implementation of Kaizen training. Indicators of the efficiency in management should be further elaborated on. First, the value of capital should be measured, and data on wage payments and the cost of additional investment, associated with the adoption of Kaizen, should be collected, to allow us to measure the total factor productivity index. Since products produced by different companies vary, a direct comparison of the total factor productivity would be absurd. We can, however, compare the growth rate of total factor productivity between Kaizen-trained and control companies. Total factor productivity is a better indicator of efficiency in management than labour productivity. We could also compute the gross profit (i.e. revenue minus wage payment) or gross profit rate (i.e. gross profit divided by the value of capital) as an alternative indicator of efficiency in production. Secondly, we could systematically analyse information on work in progress, an apparently useful indicator of performance in management that we failed to collect from all the sample firms in our questionnaire survey.

It is presumed that the impact of Kaizen training is conditioned on social cohesion between the MDs and shopfloor workers, and the commitment of the MDs to Kaizen implementation. There has been good progress in some of the OEMs using Kaizen to promote social cohesion in South Africa. Both variables are critically important but difficult to measure. Without assessing the roles of these variables, however, our analysis of the impact of Kaizen on efficiency in management will be incomplete. Indeed, the major purpose of future study will be to demonstrate the importance of 
social cohesion and the MDs' commitment to improving the performance of auto-parts sectors in South Africa.

\section{Acknowledgements}

The Authors would like to acknowledge the contribution of Kimiaki Jin, and the two Kaizen experts Kazunori Hayashi and Michiharu Suzuki, who implemented the training. Also Yuki Higuchi, Justine Barnes, and Anthony Black, as well as an anonymous reviewer and editor of this journal, for their useful comments on the earlier version of the article.

\section{Competing interests}

The authors have declared that no competing interest exists.

\section{Authors' contributions}

K.O. developed the conceptualisation and methodology, as well as wrote the original draft, N.B-M. contributed to the investigation, project administration, validation, data curation, resources, writing and reviewing and editing.

\section{Ethical considerations}

This article followed all ethical standards for research without direct contact with human or animal subjects.

\section{Funding information}

The research received no specific grant from any funding agency, even though the Japan International Cooperation Agency is willing to support the publication fees.

\section{Data availability}

The authors confirm that the data supporting the findings of this study are available within the article.

\section{Disclaimer}

The views and opinions expressed in this article are those of the authors and do not necessarily reflect the official policy or position of any affiliated agency of the authors.

\section{References}

Abadiano, B.D., 2020, Social inclusion and productivity improvement for indigenous peoples: Experiences of the Philippines, viewed 17 August 2020, from https:// youtu.be/WUDOIBObWFY.

Automotive Industry Development Centre (AIDC), 2019, Kaizen training manual (Draft), Rosslyn, Gauteng.

Bandiera, O., Lemos, R., Prat, A. \& Sadun, R., 2018, 'Managing the family firm: Evidence from COEs at work', Review of Financial Studies 31(5), 1605-1653. https://doi.org/10.1093/rfs/hhx138

Bertrand, M. \& Schoar, A., 2003, 'Managing with style: The effect of managers on firm policies', Quarterly Journal of Economics 118(4), 1169-1208. https://doi. org/10.1162/003355303322552775
Bloom, N., Benn, E., Mahajan, A., McKenzie, D. \& Roberts, J., 2013, 'Does management matter? Evidence from India', Quarterly Journal of Economics 128(1), 1-51. https://doi.org/10.1093/qje/qjs044

Bloom, N., Mahajan, A., McKenzie, D. \& Roberts, J., 2020, 'Do management interventions last? Evidence from India', American Economic Journal: Applied Economics 12(2), 198-219. https://doi.org/10.1257/app.20180369

Bloom, N. \& Van Reenen, J., 2010, 'Why do management practices differ across firms and countries?', Journal of Economic Perspectives 24(1), 203-224. https://doi. org/10.1257/jep.24.1.203

Bruhn, M., Karlan, D. \& Schoar, A., 2010, 'What capital is missing in developing countries?', American Economic Review 100(2), 629-633. https://doi.org/10.1257/ aer.100.2.629

Bruhn, M., Karlan, D. \& Schoar, A., 2018, 'The impact of consulting service on small and medium enterprises: Evidence from a randomized trial in Mexico', Journal of Political Economy 126(2), 635-687. https://doi.org/10.1086/696154

Giorcelli, M., 2019, 'The long-term effects of management and technology transfer', American Economic Review 109(1), 121-152. https://doi.org/10.1257/ aer.20170619

Harada, T., 2015, Management lessons from Taiichi Ohno, McGraw-Hill, New York, NY.

Hashino, T. \& Otsuka, K. (eds.), 2016, Industrial districts in history and the developing world, Springer, Dordrecht.

Higuchi, Y., Nam, V.H. \& Sonobe, T., 2015, 'Sustained impacts of Kaizen training', Journal of Economic Behavior and Organization 120(C), 189-206. https://doi. org/10.1016/j.jebo.2015.10.009

Higuchi, Y., Mhede, E.P. \& Sonobe, T., 2019, 'Short- and medium-run impacts of management training: An experiment in Tanzania', World Development 114(C), 220-236. https://doi.org/10.1016/j.worlddev.2018.10.002

lacovone, L., Maloney, W. \& McKenzie, D., 2019, Improving management with individual and group-based consulting, Policy Research Working Paper 854, World Bank, Washington, DC.

Imai, M., 1997, Gemba Kaizen: A commonsense, low-cost approach to management, McGraw-Hill, New York, NY.

Jin, K., 2018, 'Role of Kaizen in Japan's Overseas Development Cooperation', in K. Otsuka, K. Jin \& T. Sonobe (eds.), Applying Kaizen in Africa: A new avenue for industrial development, pp. 31-68, Palgrave Macmillan, Cham.

Kaplinsky, R., 1994, Easternization: The spread of Japanese management technique to developing countries, Frank Cass, London.

Mano, Y., Iddrisu, A., Yoshino, Y. \& Sonobe, T., 2012, 'How can micro and smal enterprises in sub-Saharan Africa become more productive? The impacts of experimental basic managerial training', World Development 40(3), 458-468. https://doi.org/10.1016/j.worlddev.2011.09.013

Madi, P.M., 2000, Leadership lessons from emperor Shaka Zulu the Great, Knowledge Resources, Randburg.

McKee, R.K., 1999, The power to change, Grid International Inc., Austin, TX.

McKenzie, D., 2020, Small business training to improve management practices in developing countries: Reassessing the evidence for 'Training Doesn't Work', Policy Research Working Paper 9408, World Bank, Washington, DC

McKenzie, D. \& Woodruff, C., 2014, 'What are we learning from business training and entrepreneurship evaluations around the developing world?', World Bank Research Observer 29(1), 1-39. https://doi.org/10.1093/wbro/lkt007

McKenzie, D. \& Woodruff, C., 2017, 'Business practices in small firms in developing countries', Management Science 63(9), 2967-2981. https://doi.org/10.1287/ mnsc.2016.2492

Otsuka, K., Jin, K. \& Sonobe, T. (eds.), 2018, Applying Kaizen in Africa: A new avenue for industrial development, Palgrave Macmillan, Cham.

Pretorius, B., 2013, In the driving seat: Lessons in leadership, Tafelberg, Cape Town.

Shimada, G. \& Sonobe, T., 2021, 'Impacts of Kaizen management on workers: Evidence from Central America and the Carribean Region', Review of Development Economics 25(3), 1492-1514. https://doi.org/10.1111/rode.12773

Sonobe, T., 2018, 'How Kaizen brightens Africa's future', in K. Otsuka, K. Jin \& T. Sonobe (eds.), Applying Kaizen in Africa: A new avenue for industrial development pp. 1-30, Palgrave Macmillan, Cham.

Sonobe, T. \& Otsuka, K., 2006, Cluster-based industrial development: An East Asian model, Palgrave Macmillan, Hampshire.

Sonobe, T. \& Otsuka, K., 2011, Cluster-based industrial development: A comparative study of Asia and Africa, Palgrave Macmillan, Hampshire.

Sonobe, T. \& Otsuka, K., 2014, Cluster-based industrial development: Kaizen management for MSE growth in developing countries, Palgrave Macmillan, Hampshire.

Sugimoto, S., 2018, 'Kaizen in practice', in K. Otsuka, K. Jin \& T. Sonobe (eds.), Applying Kaizen in Africa: A new avenue for industrial development, pp. 69-110, Palgrave Macmillan, Cham. 